\title{
Effect of Cuff Pressure on Blood Flow During Blood Flow- Restricted Rest and Exercise
}

Kent Westerberg Crossley

Brigham Young University

Follow this and additional works at: https://scholarsarchive.byu.edu/etd

Part of the Exercise Science Commons

\section{BYU ScholarsArchive Citation}

Crossley, Kent Westerberg, "Effect of Cuff Pressure on Blood Flow During Blood Flow-Restricted Rest and Exercise" (2019). Theses and Dissertations. 8259.

https://scholarsarchive.byu.edu/etd/8259

This Dissertation is brought to you for free and open access by BYU ScholarsArchive. It has been accepted for inclusion in Theses and Dissertations by an authorized administrator of BYU ScholarsArchive. For more information, please contact ellen_amatangelo@byu.edu. 


\section{Effect of Cuff Pressure on Blood Flow During}

Blood Flow-Restricted Rest and Exercise

Kent Westerberg Crossley

A dissertation submitted to the faculty of

Brigham Young University

in partial fulfillment of the requirements for the degree of

Doctor of Philosophy

J. Brent Feland, Chair

A. Wayne Johnson

Dennis L. Eggett

Jayson R. Gifford

Ulrike H. Mitchell

Department of Exercise Sciences

Brigham Young University

Copyright (C) 2019 Kent Westerberg Crossley

All Rights Reserved 


\author{
ABSTRACT \\ Effect of Cuff Pressure on Blood Flow During \\ Blood Flow-Restricted Rest and Exercise \\ Kent Westerberg Crossley \\ Department of Exercise Sciences, BYU \\ Doctor of Philosophy
}

Purpose: The purpose of this study was to investigate the blood flow/pressure relationship (linear or nonlinear) in the superficial femoral artery when seated, as well as to investigate blood flow changes with exercise using varying cuff pressures and a preexercise (PE) condition. The presence of venous outflow with occlusion at rest and exercise was also investigated.

Methods: Twenty-three subjects visited the lab on 3 occasions. First to determine linearity of blood flow using $0 \%$ to $90 \%$ arterial occlusion pressure (AOP), and venous outflow at rest and during exercise with cuff inflated to $40 \%$ AOP. Subsequent visits compared blood flow between rest and PE conditions to determine average blood flow, heart rate, systolic and diastolic blood pressure changes in response to a blood flow-restricted (BFR) exercise protocol.

Results: Blood flow/pressure relationship is nonlinear at the superficial femoral artery ( $\mathrm{p}$ $<0.01)$. No significant differences in average blood flow, conductance or mean arterial pressure (MAP) were found between $30 \%$ to $80 \%$ AOP ( $p=1.0$ to .08). Blood flow is not significantly different between rest and PE groups $(\mathrm{p}=0.49)$ although initial $40 \%$ AOP and $40 \%$ exercise arterial occlusion pressure (EAOP) values were different between rest and PE groups. $(p<0.01)$.

Conclusion: The nonlinear relationship at the superficial femoral artery demonstrates higher cuff pressures are not necessary to reduce blood flow in BFR exercise of the lower extremity. Furthermore, PE or warm-up is not necessary prior to determining EAOP as it does not alter blood flow responses during BFR exercise. We found evidence of venous outflow above the cuff both at rest and during exercise at $40 \%$ AOP.

Keywords: relative BFR, arterial occlusion pressure, nonlinear 


\section{ACKNOWLEDGEMENTS}

I want to express great appreciation to my committee members for guiding and directing me throughout my dissertation. I would especially like to thank my mentor and chair, Dr. J. Brent Feland, for his patience, direction, time and calming influence.

I would also like to thank my undergraduate research assistants, Tabitha Caldwell, Doran Porter and Josh Ellsworth. Your presence throughout data collection was most needed. I could not have completed it without you.

I would like to express my love and gratitude for my family and for all of their encouraging words. I would like to express my love to my kids who understood that dad had work to do. Most importantly, I want to thank my wife, Heather, for all the support, love, encouragement and undying devotion throughout my schooling and our entire marriage. I could not have done this without you. 


\section{Table of Contents}

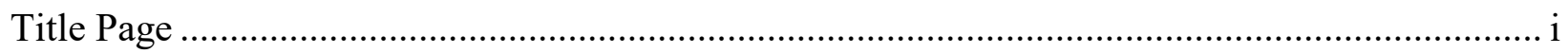

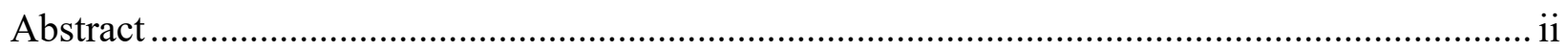

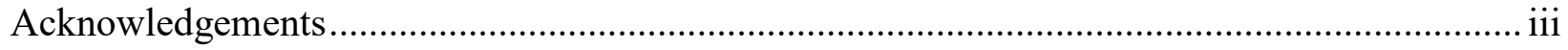

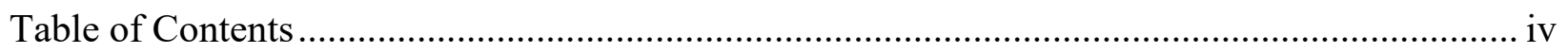

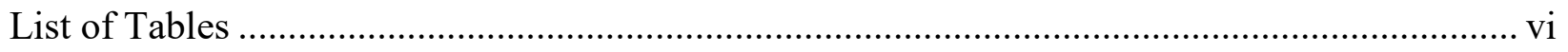

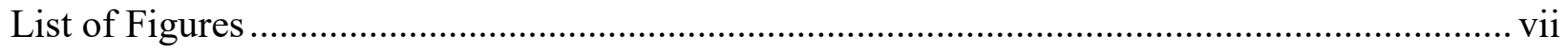

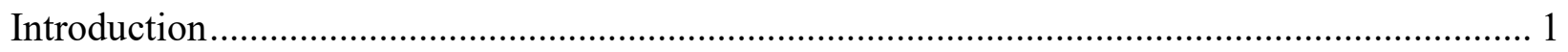

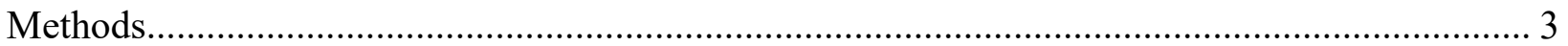

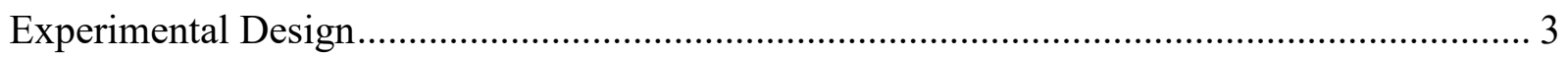

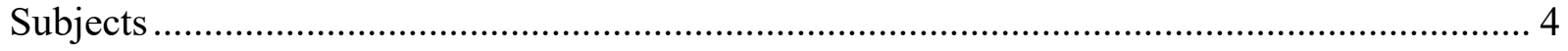

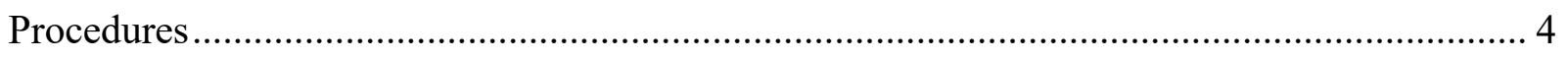

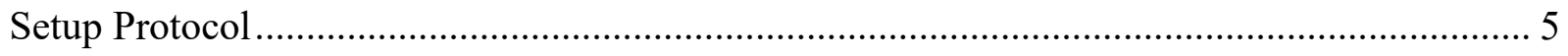

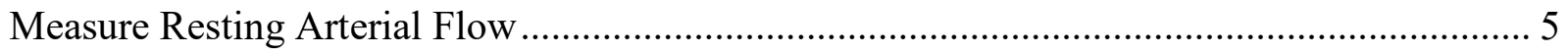

Measure Arterial Occlusion Pressure........................................................................ 6

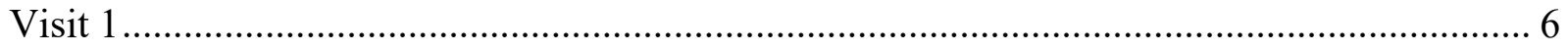

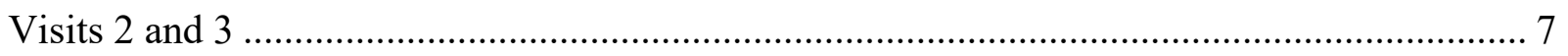

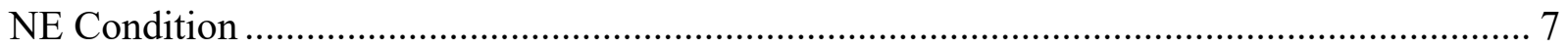

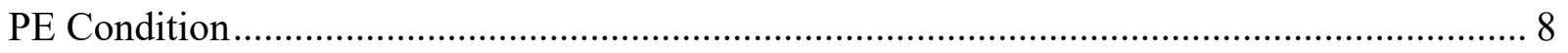

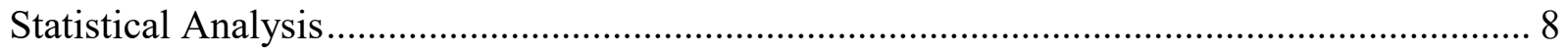

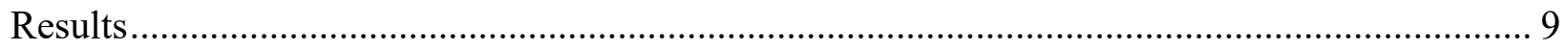

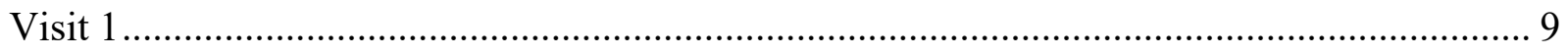

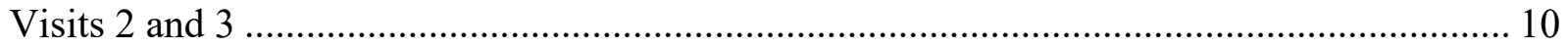




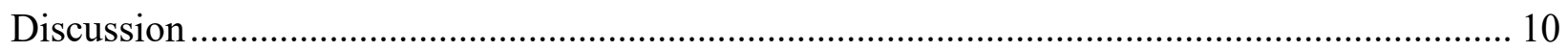

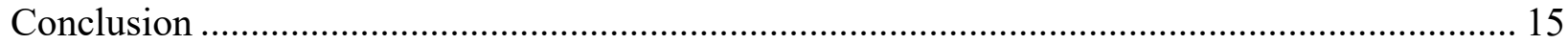

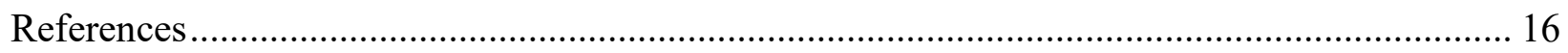




\section{List of Tables}

Table 1: Percent change in blood flow response to occlusion pressures ..................................... 19

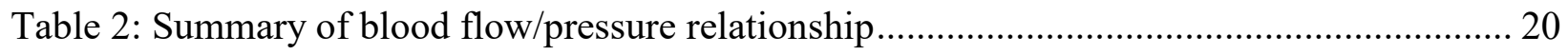

Table 3: Summary of blood flow and hemodynamic measurements for within-group comparisons 


\section{List of Figures}

Figure 1: Blood flow/pressure relationship..................................................................... 22

Figure 2: Vascular conductance (average blood flow / MAP) by \%AOPs with respective CIs

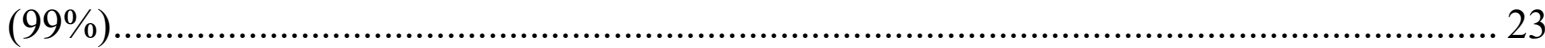

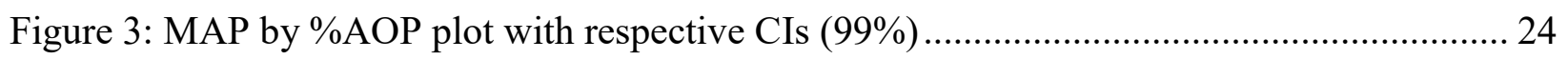

Figure 4: AOP and 40\% AOP for left and right legs as well as NE and PE groups.................. 25

Figure 5: Blood flow comparisons between no exercise and preexercise. ................................ 26 


\section{Introduction}

The concept of exercise training with blood flow restriction (BFR) has been around for nearly 40 years and was popularized in Japan by Yoshiaki Sato in the mid-1980s (1) and seeks to increase strength and muscle hypertrophy (2) with as little weight as $20 \%$ of a 1 repetition maximum (1RM) (3). BFR exercise commonly utilizes a pneumatic cuff, which surrounds the proximal end of the exercising limb (1). The cuff pressure is thought to occlude venous return and cause a decrease in arterial blood flow and velocity distal to the cuff (1). Restricting venous blood flow results in acute venous pooling and muscular swelling distal to the cuff $(4,5)$ which reduces intramuscular oxygen delivery (6) and decreases venous clearance of metabolites (7). This leads to exaggerated levels of metabolic acidosis within the active skeletal muscle and reduced time to fatigue during resistance exercise sets $(8,9)$. Application of cuff pressures to reduce blood flow is dependent on a few different variables such as cuff size, material, and extremity circumference. Ultimately, the goal of BFR exercise methods is to create a reproducible stimulus across subjects. The application of suggested pressures has changed over the course of BFR studies $(3,10,11)$, but is still a topic of concern.

Protocols for BFR have varied in the application of cuff pressures. Earlier BFR studies used absolute pressures $(250 \mathrm{~mm} \mathrm{Hg})(10,12,13)$; while others have set relative pressures based solely on the brachial systolic blood pressure of each individual $(11,14,15)$. In an effort to minimize arterial occlusion and standardize BFR occlusion pressures (same stimulus) across all individuals, research has moved towards determining total arterial occlusion pressure (AOP) (minimum pressure applied by the cuff to completely occlude arterial flow) of each subject by Doppler ultrasound, and then use a set relative percentage of AOP (\%AOP) during BFR exercise $(3,16)$. Using \%AOPs helps standardize the application of BFR and reduces the likelihood that 
participants are placed in full arterial occlusion during rest or exercise, thus improving the safety of the BFR stimulus (17).

Utilizing the lowest possible pressure to achieve a training response is considered the safest BFR training application, and it is also advantageous as it is perceptually less stressful to the individual performing the training, which in turn can improve exercise/therapeutic treatment adherence (18). Performing BFR exercises at higher \%AOP does not necessarily equate to greater muscle hypertrophy, but does result in higher ratings of perceived discomfort compared to lower occlusion pressures (19). Low-load resistance exercise training in combination with either $40 \%$ or $90 \%$ AOP produced similar increases in muscle size, strength, and endurance in the upper extremity (19). This suggested that the relationship between arterial occlusion and blood pressure is not linear, and that $40 \%$ AOP may be all that is needed to maximize the anabolic response to low-load BFR training (19). However, since exercise increases blood pressure (20-22), Barnett et al reported an increase in AOP from preexercise to immediately postexercise and suggested a $40 \%$ AOP obtained during rest was equal to $32 \%$ immediately postexercise (23). This presents a potential issue where \%AOP may decrease below the suggested occlusion training range, even if cuff pressure remains the same, which could limit the desired outcomes of the BFR stimulus. It would be beneficial to investigate whether this drop can be mitigated or whether it is even important to control for this decrease. This change has only been shown in the upper arm, and the magnitude and timing of this decrease is presently unknown and warrants further research (23).

Even though it is common practice to utilize a warm-up prior to performing a physical test such as a $1 \mathrm{RM}(10,19,23-25)$, research has not reported on the effect of preexercise (PE) on the starting \%AOP. Therefore, additional research is needed to determine if exercising prior to 
determining AOP will influence both the PE and postexercise AOP change as reported by Barnett et al (23). Determining if PE will both adjust and prevent a drop in the \%AOP may be important for determining how to improve the methodological approach to the application of \%AOPs for BFR exercise.

Body position is another important consideration when evaluating \%AOP. Measurement of AOP in the posterior tibial artery has been reported to increase from the supine to seated position (26). Arterial blood flow has been reported to decrease with increasing cuff pressure in a linear fashion in the posterior tibial artery in the supine position (27) as opposed to a nonlinear fashion in the brachial artery in a standing position (28). Further research is needed to determine if blood flow response in the lower extremities is linear or nonlinear in a seated position. Furthermore, no study to date has established the presence of venous outflow proximal to the cuff either before or during BFR exercise. Since the goal of BFR is to occlude venous outflow (24), it is important to determine if the current suggested protocol of $40 \%$ AOP is sufficient to accomplish this. Therefore, the aim of this study was to: 1) determine if blood flow in the lower leg exhibits a linear or nonlinear response to variable \%AOPs; 2) determine if $\mathrm{PE}$ alters both starting \%AOP and blood flow through a BFR exercise protocol; and 3) to assess the presence of venous outflow at rest and during BFR exercise.

\section{Methods}

\section{Experimental Design}

The study used a randomized crossover design, where each subject served as his or her own control in each of the experiments. 
Subjects

Twenty-three subjects (11 male, 12 female; $175.2 \pm 7.95 \mathrm{~cm}, 70.33 \pm 11.45 \mathrm{~kg}$, and 22.78 \pm 2.21 years $[$ mean $\pm \mathrm{SD}])$ were recruited from a university setting. All subjects were classified as being recreationally active (defined in this study as exercising at least 3x/wk for 30 min or more per exercise session). Participants were excluded if they had more than one of the following risk factors for thromboembolism (29), which included the following: obesity (BMI $\geq$ $30 \mathrm{~kg} \cdot \mathrm{m}^{2}$ ); diagnosed Crohn's disease, past fracture of the hip, pelvis or femur; major surgery within the last 6 months; varicose veins; a family or personal history of deep vein thrombosis or pulmonary embolism.

Procedures

Subjects reported to the lab for an initial orientation meeting, and to be screened for all qualification factors included above, and to read and sign an university IRB-approved informed consent. Qualified subjects had anthropometric measurements recorded and a 1RM assessed for ankle plantar flexion on a Hammer Strength selectorized leg press (Life Fitness, Inc., Schiller Park, IL, USA). The assessment of the 1RM was completed using an established protocol (30). Subjects were instructed to wear loose fitting exercise shorts each day they reported to lab (3 visits total), as well as to avoid exercise within 24-h, be in a 4-h fasting state, and to abstain from caffeine for at least 8-h prior to testing. The first phase (visit 1) for each subject was designed to assess whether the change in blood flow in the superficial femoral artery was linear in response to different \%AOPs, while measured in a seated position. Phase two involved two separate days (visits $2 \& 3$ ) to determine if utilizing $40 \%$ AOP changed blood flow in a PE vs. no preexercise condition (NE, no exercise prior to determining AOP). 


\section{Setup Protocol}

Each day subjects reported to the lab, the following setup protocol included an acclimation procedure followed by measurement of resting blood flow and resting AOP. An uninflated $10 \mathrm{~cm}$ Hokanson cuff (Hokanson E20, Hokanson, Inc., Belleview, WA, USA) was placed on the upper thigh near the inguinal crease of the selected leg. Subjects were seated in a specialized chair and a continuous noninvasive arterial pressure monitor (CNAP) and finger photoplethysmography blood pressure monitor (CNSystems Medizintechnik Graz, Austria) was placed on the subject's right arm along with the second and third fingers for continuous measurement of 6 hemodynamic factors (heart rate, stroke volume, cardiac output, systolic and diastolic blood pressure, and mean arterial pressure (MAP). Biopac Acqknowledge 4.0 data acquisition software (Biopac Systems, Inc., Goleta, CA, USA) was used for collection of data captured by the CNAP. Subjects then remained in a seated position for 30 min to establish a "resting" condition. A recalibration of the CNAP was completed approximately every 15 min to ensure accuracy. Subjects remained in this seated position for the entirety of the data collecting session.

Measure Resting Arterial Flow

Following the setup protocol, resting blood flow was measured over the superficial femoral artery $(60 \%$ of the distance from the anterior superior iliac spine to the top edge of the patella) just distal to the inferior border of the cuff using a $9 \mathrm{MHz}$ ultrasound sound probe (Logiq e, 9L probe; General Electric Company, Fairfield, CT, USA). Ultrasound gel (Aquasonic 100, Parker Laboratories, Inc., Fairfield, NJ, USA) was used as a medium between the sound head and the subject's skin. Insonation angle of the probe was set and maintained at $60^{\circ}$. Doppler velocity waveforms (DVW) and color flow mode (CFM) was inspected for the presence of 
arterial blood flow through the superficial femoral artery. Once a clear visualization of the artery was obtained, resting blood flow was recorded for $60 \mathrm{~s}$. The Doppler ultrasound recordings were used to determine vessel diameter along with antegrade, retrograde and average blood flow. Measure Arterial Occlusion Pressure

Once resting arterial blood flow measurements were completed, AOP was measured. The cuff was inflated to $50 \mathrm{~mm} \mathrm{Hg}$ for $30 \mathrm{~s}$ and then deflated for $10 \mathrm{~s}$, each additional inflation was increased by $30 \mathrm{~mm} \mathrm{Hg} \mathrm{(30} \mathrm{s} \mathrm{on,} 10 \mathrm{~s}$ off) until blood flow had been occluded. Occlusion was determined by DVW (no tracings) and CFM (no color). Once occluded, the pressure was decreased in increments of $10 \mathrm{~mm} \mathrm{Hg} \mathrm{(30} \mathrm{s} \mathrm{on,} 10 \mathrm{~s}$ off) until blood flow reappeared. Pressure was then increased $1 \mathrm{~mm} \mathrm{Hg}$ until blood flow was no longer detected. The lowest pressure at which arterial blood flow was occluded became the AOP. Once AOP was determined, the cuff was deflated and subjects rested quietly for $5 \mathrm{~min}$.

Visit 1

The experimental leg was randomly selected on visit 1 (legs were alternated for all other visits). Relative AOPs were calculated and measured in randomized fashion (eg, 10\%, 20\%, $30 \%, 40 \%, 50 \%, 60 \%, 70 \%, 80 \%$, and $90 \%$ ) for each subject in order to account for possible time order effects with the application of the various cuff pressures. Each percentage was calculated based upon the individual's AOP. The cuff was then inflated to the randomized relative pressure and a Doppler ultrasound measurement of the superficial femoral artery was recorded for $60 \mathrm{~s}$. The cuff was then deflated and subjects rested for a period of 5 min followed by another relative pressure measurement until all \%AOPs and Doppler ultrasound measurements were recorded. After all \%AOP measurements were completed, subjects rested another $15 \mathrm{~min}$ in the same sitting position prior to assessment of venous flow. 
A no-exercise, time-matched control group was used to assess the influence of BFR and time on the venous system. While our original interest lies in determining if the muscle pump is sufficient to overcome BFR pressure in the cuff, we were also interested in determining if the buildup of pressure in the venous system over time from the application of BFR would overcome cuff pressure independent of exercise/muscle pump. To assess this, cuff pressure was increased to $40 \%$ AOP for $60 \mathrm{~s}$ and venous blood flow was monitored just proximal to the superior border of the cuff in the femoral triangle without leg movement or exercise. After 5 min of rest, a Velcro foot strap was attached to the subject's forefoot. The strap was connected to a weighted cable pulley (NK664-75 DeLuxe wall pulley, NK Products, Lake Elsinore, CA, USA) at 20\% of their 1RM. The cuff was inflated to $40 \%$ AOP and subjects completed 60 s of plantar flexion activity while Doppler ultrasound measurements were taken of the femoral vein just proximal to the cuff to assess venous blood flow. This exercise was performed at a tempo of $1 \mathrm{~s}$ (paced by a metronome) in each direction. The subjects were instructed to complete each phase of the lift (concentric/eccentric) and not let the weight fall back to the original starting position. This was done to determine if venous blood flow remained occluded throughout the $60 \mathrm{~s}$ activity.

Visits 2 and 3

All subjects completed a plantar flexion BFR exercise bout under 2 conditions in random order over the next 2 visits (NE, PE). Subjects returned to the lab 2 days following visit 1 procedures. Subjects used the opposite leg than that used in visit 1. NE Condition

Following the setup protocol, a Velcro ${ }^{\mathrm{TM}}$ strap attached to a cable pulley was placed around the forefoot with the weight set to $20 \%$ of 1 RM. The cuff was then inflated to $40 \%$ AOP as determined in the setup protocol. Subjects then completed a 4-set series of 30-15-15-15 
repetitions of plantar flexion exercise at a tempo (metronome) of $1 \mathrm{~s}$ each concentric/eccentric phase with a $60 \mathrm{~s}$ rest period between each set. Subjects were again instructed to not let the weight fall back to the original starting position. The $9 \mathrm{MHz}$ probe was placed over the superficial femoral artery and kept in place for continuous measurements throughout the entire measurement period. The Doppler ultrasound recordings were used to determine average blood flow.

PE Condition

Following the setup protocol, we determined the subject's arterial occlusion pressure during exercise (EAOP). Subjects began PE performing plantar flexion exercise with $20 \%$ of 1RM attached around the forefoot. Blood flow of the superficial femoral artery was monitored via Doppler ultrasound for 2 to 3 min of continuous exercise. A 60 s recording of peak blood flow was then taken as they continued exercise. The cuff was then inflated to resting AOP and adjusted as needed to establish EAOP.

After subjects had rested for $20 \mathrm{~min}$, the cuff was inflated to $40 \%$ of EAOP and the same exercise and measures described in the NE condition were followed. Subjects performed the same protocol as the 4-set series of plantar flexion exercises as the NE condition. The same absolute weight was used for both conditions.

Statistical Analysis

A mixed model analysis of variance (ANOVA) with blocking on subjects was used to determine significance in our studies. A Tukey post hoc test was performed to determine level of significance. All data was analyzed using JMP Pro version 14.0 (JMP, Cary, NC, USA). Our statistical significance was set at $\mathrm{P} \leq 0.01$. Comparisons of $\% A O P$ s and their effects on average 
blood flow, antegrade and retrograde blood flow, vessel diameter, conductance, and hemodynamic factors previously listed in the setup protocol were analyzed.

Results

Visit 1

Average blood flow (fitted mean) was compared at rest ( $0 \%$ occlusion) to incremental increases (10\% to $90 \%)$ in relative occlusion pressure. A significant relationship found between different \%AOPs and resting blood flow demonstrated that the relationship between pressure and blood flow in the lower extremity is nonlinear in a seated position. A significant lack-of-fit test $(\mathrm{p}<0.0001)$ determined that a straight line does not fit our nonlinear model for average blood flow. Average blood flow at $10 \%$ AOP is significantly different than $50 \%$ to $100 \%$ AOP $(\mathrm{p}<$ 0.0002 ) and $20 \%$ is different from $80 \%$ to $100 \%$ AOP ( $p$ value range $=0.009$ to $<0.0001$ ) however, between $30 \%$ to $80 \%$ AOP blood flow values were not significantly different ( $\mathrm{p}$ value range $=1.0$ to 0.08$)$ from one another. Our resting condition $(0 \%)$ as well as $90 \%$ and $100 \%$ AOP were significantly different from all other conditions $(\mathrm{p} \leq 0.0002)$. A representation of blood flow at different occlusion pressures is demonstrated in Figure 1.

Vascular conductance was also compared to all \%AOPs. Significant differences were found in conductance $(\mathrm{p}<0.01)$ with decreases in nearly an identical manner as blood flow at differing \%AOPs (see Figure 2). However, no significance was found in MAP $(p=0.8)$ at differing \%AOPs (see Figure 3). A summary of our results for visit 1 can be found in Table 2 .

Ultrasound measurements of the femoral vein during our resting control condition showed evidence of venous outflow at $40 \%$ AOP (ie, visible wave forms and color flow) as well as during plantar flexion exercise. 
Visits 2 and 3

A significant difference was found in AOP $(\mathrm{p}<0.01)$ between NE $(201.49 \mathrm{~mm} \mathrm{Hg})$ and PE (228.87 mm Hg) groups as well as a significant difference in occlusion pressures between legs ( $\mathrm{p}<0.01$ ) with the right leg averaging $235.7 \mathrm{~mm} \mathrm{Hg}$ compared to $194.6 \mathrm{~mm} \mathrm{Hg}$ on the left leg (see Figure 4a). There was also a significant difference $(p<0.01)$ in $40 \%$ AOP between legs (left $78 \mathrm{~mm} \mathrm{Hg}$, right $94 \mathrm{~mm} \mathrm{Hg}$ ) and groups (NE $80.5 \mathrm{~mm} \mathrm{Hg}$, PE $91.4 \mathrm{~mm} \mathrm{Hg}$ ) (see Figure $4 b)$.

We found no significant difference $(p=0.49)$ in average blood flow between NE $(209.26$ $\mathrm{mL} / \mathrm{m})$ and PE conditions $(224.84 \mathrm{~mL} / \mathrm{m})$. We then compared blood flow between the 4 sets of exercise (30-15-15-15) and associated rest periods. We found that during exercise, blood flow was significantly greater $(\mathrm{p}<0.01)$ during the first 30 repetitions, however, there was no difference in blood flow between the next 3 sets of 15 repetitions. Blood flow was significantly greater during all exercise bouts than all resting periods $(\mathrm{p}<0.01)$, and blood flow was also significantly different $(\mathrm{p}<0.01)$ for rest periods 1,2 , and 4 than blood flow at rest. Blood flow was not different between rest and rest period $3(p>0.01)$ (see Figure 5). A summary of the within-group comparisons and their levels of significance can be found in Table 3 below.

\section{Discussion}

Our results for visit 1 show that the relationship between cuff-induced pressure and blood flow in the superficial femoral artery is nonlinear when measured in a seated position. This is contrary to the findings of Mouser et al (27), who reported a linear blood flow/pressure relationship in the posterior tibial artery, however, consistent with a previously reported (17) nonlinear blood flow/pressure relationship in the brachial artery. Both studies were performed in the supine position $(17,27)$. Since the site of occlusion in our study was similar to Mouser et al 
(27), the difference may be due to measurement of blood flow at a different site (artery) and/or different positioning of the subject. With regards to position in non-BFR studies, Wu et al reported shear rates in the superficial femoral artery to be lower than the brachial artery when measured in a supine position (31). Newcomer et al later studied superficial femoral and brachial artery responses (shear rates, diameter and blood velocity) in supine to sitting and standing (32). They reported that the superficial femoral artery demonstrated no significant difference in blood flow, mean blood velocity, conductance and diameter (32). For the brachial artery they reported no significant effect of position on blood flow, conductance and diameter, however, they noted that maximum blood velocity was reduced in standing compared to both seated and supine positions (32). It is possible that change in the blood pressure gradient caused by a difference in the hydrostatic column may play a role in our results, however, when normalizing blood flow for MAP (ie, vascular conductance) the nonlinear relationship persisted (see Figure 2), challenging the role of a hydrostatic effect on blood pressure in our nonlinear response.

The nonlinear relationship between \%AOP and flow in our study could potentially be explained by either a compensatory increase in perfusion pressure with cuffing to maintain a relatively constant flow from $30 \%$ to $80 \%$ AOP, or a nonlinear effect of cuff pressure on the vasculature deep to the tissue. Vascular conductance, which is flow normalized for perfusion pressure, is indicative of the role of artery diameter in determining flow. Both vascular conductance and MAP responses support our nonlinear findings. We found no significant interactions $(\mathrm{p}=0.83)$ between MAP and occlusion pressure (see Figure 3), which supports our finding that pressure did not increase to maintain blood flow. The MAP was unchanged and unrelated to \%AOP, supporting the notion that a compensatory increase in perfusion is not the cause of the nonlinear effect of \%AOP on blood flow. The relationship between \%AOP and 
vascular conductance was explored in order to determine if the nonlinear relationship between \%AOP and flow could be explained by a nonlinear effect of the cuff pressure on the artery. As illustrated in Figure 2, vascular conductance exhibited a nonlinear relationship with \%AOP, suggesting that the effect of the cuff pressure on the artery deep to the cuff was not linear. This could be potentially due to movement of the tissues from the cuffing pressure producing unequal pressure distribution. However, due to the inability to view the artery deep to the cuff, a direct measure of artery diameter was unavailable.

In our study, we also compared blood flow response between two different starting \%AOP conditions (NE and PE) during visits 2 and 3. We hypothesized that the starting \%AOP measured at rest may not provide a sufficient compensatory reduction in blood flow with increases in exercising blood pressure. Initially we expected that PE would alter starting AOP and could offset the effect noted by Barnett et al (23), who reported that \%AOP decreased from $40 \%$ to $32 \%$ following a traditional $30-15-15-15$ BFR exercise set due to an increase in AOP resulting from exercise (23). Having not analyzed our data from visit 1 beforehand, we used 40\% resting AOP (NE) and 40\% of EAOP (PE) during exercise in an attempt to control for the effect reported by Barnett et al (23). We found a significant difference in starting \%AOP for each condition with EAOP (PE) being $11 \mathrm{~mm} \mathrm{Hg}$ higher than the resting AOP (Figure 4b). If the relationship between AOP and blood flow was linear, this would likely result in a smaller reduction in blood flow with cuff occlusion during exercise than anticipated. Yet, in agreement with our nonlinear blood flow/pressure findings (Figure 1), the nonlinear relationship between $\%$ AOP and blood flow meant that the increase in pressure applied to the leg with EAOP and resting AOP had no impact in blood flow during plantar flexion exercise (Figure 5). These findings support the idea that when performing BFR exercise, establishing a resting \%AOP is 
sufficient. Further supporting this notion, a post hoc analysis showed no significant change in blood pressure between our NE and PE groups (systolic $\mathrm{p}=0.39$, diastolic $\mathrm{p}=0.34$ ), however, there were interset differences in systolic and diastolic blood pressure, heart rate, cardiac output, and MAP within group as expected (see Table 3).

We noted venous outflow proximal to the cuff at rest and during plantar flexion exercise while the cuff was inflated to $40 \%$ AOP. We feel that venous outflow warrants further research based on the stated goal of BFR exercise to restrict arterial blood supply to the muscle and occlude venous return (24). This is thought to initiate a cascade of events ending in the reported muscular adaptations (4-9).

Results of our study have significant clinical and practical implications for the application of pressure during BFR exercise. Our data suggest that blood flow does not change significantly between the use of $30 \%$ to $80 \%$ AOP in the superficial femoral artery, suggesting no need to increase $\% \mathrm{AOP}$ above $30 \%$ for blood flow restriction exercise in the lower extremity when considering hemodynamic responses only. Occlusion pressure was previously shown to be directly related to pain and rating of perceived exertion (33). Furthermore, it has been reported that wider cuffs cause inherently more tissue compression at any given pressure than narrow cuffs (5) and elevated pressures increase the rating of both perceived exertion and perceived pain even when comparing different cuff sizes (22).

Studies have shown that BFR exercise can result in muscle hypertrophy and strength increases (10,34-36), and comparisons have been made between BFR exercise and highintensity resistance training (10,36-38). A recent meta-analysis suggests that while both forms of resistance training result in expected muscle adaptations (ie, strength, hypertrophy, activation), high intensity resistance training tends to show slightly greater strength and activation responses 
while hypertrophy responses are similar (33). The greater gains in strength from high intensity resistance training could be a result of level of activation of muscle needed for higher loads as well as the overall load/volume difference when making comparisons between these two protocols (33). Although various muscle adaptations are to be expected from BFR exercise, previous studies have varied in the cuff sizes and pressures used to report such findings. To date, it has been suggested that cuff width does not have a significant effect on muscle size and strength gains in the upper extremity when using the same relative pressure after a long term (12 wk) training protocol (34). Conversely, in a 12-wk lower extremity study, BFR across a combination of $20 \%$ to $40 \% 1 \mathrm{RM}$ at either $40 \%$ or $80 \%$ AOP produced similar muscle strength gains, but muscle mass changes were only found utilizing work at the lower intensity ( $20 \%$ 1RM) with both occlusion pressures (39). Specific comparisons utilizing lower \%AOPs are limited in the current body of literature. In a recent study by Counts et al, (19) it was reported that low-load exercise utilizing either $40 \%$ or $90 \%$ AOP on opposite arms produced similar increases in muscle size, strength, and endurance in the upper extremity. It was also noted that the higher pressure condition produced higher ratings of discomfort throughout the training program (19). Considering our results, future studies are needed to compare lower \%AOPs (30\% to $40 \%$ ) to determine if adaptive muscle responses are comparable to prior research in the lower extremity (35,36). Counts et al (19) also suggested that the first set of 30 repetitions may be the most important stimulus and that hypertrophic responses can be maximized with fewer reps as long as the muscle reaches maximal fatigue. Future studies on repetitions and sets for BFR exercise are needed to determine the number of sets/repetitions needed to maximize skeletal muscle fatigue, improve muscular adaptations and minimize rating of perceived pain. 
During the course of our study we noted a significant interleg difference $(p<0.0001)$ in AOPs (fitted mean: left $195 \mathrm{~mm} \mathrm{Hg}$, right $236 \mathrm{~mm} \mathrm{Hg}$ : range L: 145-270 mm Hg, R: 168-300 mm Hg) as well as in \%AOPs (left $78 \mathrm{~mm} \mathrm{Hg}$, right $94 \mathrm{~mm} \mathrm{Hg}$ : range L: 58-108 mm Hg, R: 67-120 mm $\mathrm{Hg}$ ). Additional research into AOP differences between legs and leg dominance needs to be completed in order to determine the salience of this finding.

Our results were limited to subjects being placed in a seated position, cuff size $(10 \mathrm{~cm})$, and inflation device (Hokanson E-20 Rapid Cuff Inflator). There are several other types of devices (Kaatsu, B-strong, Delphi) that can be utilized for exercise, whereas Hokanson is primarily a clinical device. The Kaatsu and B-strong bands can be disconnected from the inflation device and worn during normal exercise bouts in any position. We also delimited our population to healthy young adults. BFR research on older adults has shown to be beneficial for muscle adaptations as well (40), but does tend to increase both systolic and diastolic pressures at low work loads more than high intensity repetitions without BFR (41). To date the linearity of blood flow has only been studied in a younger population $(17,27,28)$ and it remains unknown if age plays a factor in the relationship between blood flow and \%AOPs.

\section{Conclusion}

Our nonlinear relationship between pressure and blood flow results match those results of the upper body with blood flow being stable from $30 \%$ to $80 \%$ AOP. Adjusting for AOP following PE or possibly warm-up exercise does not appear to be warranted since blood flow responses are similar to the use of resting AOP. Consequently, small differences in cuff pressure during exercise have no effect on exercising blood flow. Lower \%AOPs allow for BFR training to be more comfortable, have a comparable stimulus, and may provide similar muscle adaptive responses, although future research is needed to verify this. 


\section{References}

1. Manini TM, Clark BC. Blood flow restricted exercise and skeletal muscle health. Exerc Sport Sci Rev. 2009 Apr;37(2):78-85.

2. Yasuda T, Loenneke JP, Thiebaud RS, Abe T. Effects of blood flow restricted lowintensity concentric or eccentric training on muscle size and strength. PLoS One [Internet]. 2012 [cited 2018 Mar 19];7(12):e52843. Available from: http://www.ncbi.nlm.nih.gov/pubmed/23300795.

3. Laurentino GC, Ugrinowitsch C, Roschel H, Aoki MS, Soares AG, Neves M, et al. Strength training with blood flow restriction diminishes myostatin gene expression. Med Sci Sports Exerc. 2012 Mar;44(3):406-12.

4. Iida H, Takano H, Meguro K, Asada K, Oonuma H, Morita T, et al. Hemodynamic and autonomic nervous responses to the restriction of femoral blood flow by KAATSU. Int $J$ KAATSU Train Res. 2005;1(2):57-64.

5. Loenneke JP, Fahs CA, Rossow LM, Sherk VD, Thiebaud RS, Abe T, et al. Effects of cuff width on arterial occlusion: implications for blood flow restricted exercise. Eur $J$ Appl Physiol. 2012 Aug;112(8):2903-12.

6. Tanimoto M, Madarame H, Ishii N. Muscle oxygenation and plasma growth hormone concentration during and after resistance exercise: Comparison between "KAATSU" and other types of regimen. Int J KAATSU Train Res. 2005;1(2):51-6.

7. Inagaki Y, Madarame H, Neya M, Ishii N. Increase in serum growth hormone induced by electrical stimulation of muscle combined with blood flow restriction. Eur J Appl Physiol. 2011 Nov;111(11):2715-21.

8. Loenneke JP, Wilson JM, Balapur A, Thrower AD, Barnes JT, Pujol TJ. Time under tension decreased with blood flow-restricted exercise. Clin Physiol Funct Imaging. 2012 Jul;32(4):268-73.

9. Wernbom M, Augustsson J, Thomeé R. Effects of vascular occlusion on muscular endurance in dynamic knee extension exercise at different submaximal loads. $J$ strength Cond Res. 2006 May;20(2):372-7.

10. Takarada Y, Takazawa H, Sato Y, Takebayashi S, Tanaka Y, Ishii N. Effects of resistance exercise combined with moderate vascular occlusion on muscular function in humans. $J$ Appl Physiol. 2000 Jun;88(6):2097-106.

11. Clark BC, Manini TM, Hoffman RL, Williams PS, Guiler MK, Knutson MJ, et al. Relative safety of 4 weeks of blood flow-restricted resistance exercise in young, healthy adults. Scand J Med Sci Sports. 2011 Oct;21(5):653-62.

12. Sumide T, Sakuraba K, Sawaki K, Ohmura H, Tamura Y. Effect of resistance exercise training combined with relatively low vascular occlusion. J Sci Med Sport. 2009 Jan;12(1):107-12.

13. Nielsen JL, Aagaard P, Bech RD, Nygaard T, Hvid LG, Wernbom M, et al. Proliferation of myogenic stem cells in human skeletal muscle in response to low-load resistance training with blood flow restriction. J Physiol. 2012 Sep;590(17):4351-61.

14. Cook SB, Clark BC, Ploutz-Snyder LL. Effects of exercise load and blood-flow restriction on skeletal muscle function. Med Sci Sports Exerc. 2007 Oct;39(10):1708-13.

15. Cook SB, LaRoche DP, Villa MR, Barile H, Manini TM. Blood flow restricted resistance training in older adults at risk of mobility limitations. Exp Gerontol. 2017 Dec;99:138-45.

16. Laurentino G, Ugrinowitsch C, Aihara A, Fernandes A, Parcell A, Ricard M, et al. Effects 
of strength training and vascular occlusion. Int J Sports Med. 2008 Aug;29(08):664-7.

17. Mouser JG, Dankel SJ, Jessee MB, Mattocks KT, Buckner SL, Counts BR, et al. A tale of three cuffs: the hemodynamics of blood flow restriction. Eur J Appl Physiol. 2017 Jul;117(7):1493-9.

18. Vanwye WR, Weatherholt AM, Mikesky AE. Blood flow restriction training: implementation into clinical practice. Int J Exerc Sci. 2017 Sep;10(5):649-54.

19. Counts BR, Dankel SJ, Barnett BE, Kim D, Mouser JG, Allen KM, et al. Influence of relative blood flow restriction pressure on muscle activation and muscle adaptation. Muscle and Nerve. 2016 Mar;53(3):438-45.

20. Brandner CR, Kidgell DJ, Warmington SA. Unilateral bicep curl hemodynamics: Lowpressure continuous vs high-pressure intermittent blood flow restriction. Scand J Med Sci Sports. 2015 Dec;25(6):770-7.

21. Downs ME, Hackney KJ, Martin D, Caine TL, Cunningham D, O'Connor DP, et al. Acute vascular and cardiovascular responses to blood flow-restricted exercise. Med Sci Sports Exerc. 2014 Aug;46(8):1489-97.

22. Rossow LM, Fahs CA, Loenneke JP, Thiebaud RS, Sherk VD, Abe T, et al. Cardiovascular and perceptual responses to blood-flow-restricted resistance exercise with differing restrictive cuffs. Clin Physiol Funct Imaging. 2012 Sep;32(5):331-7.

23. Barnett BE, Dankel SJ, Counts BR, Nooe AL, Abe T, Loenneke JP. Blood flow occlusion pressure at rest and immediately after a bout of low load exercise. Clin Physiol Funct Imaging. 2016 Nov;36(6):436-40.

24. Dankel S, Buckner S, Counts B, Jessee M, Mouser J, Mattocks K, et al. The acute muscular response to two distinct blood flow restriction protocols. Physiol Int. 2017 Mar;104(1):64-76.

25. Buckner SL, Dankel SJ, Counts BR, Jessee MB, Mouser JG, Mattocks KT, et al. Influence of cuff material on blood flow restriction stimulus in the upper body. J Physiol Sci. 2017 Jan;67(1):207-15.

26. Sieljacks P, Knudsen L, Wernbom M, Vissing K. Body position influences arterial occlusion pressure: implications for the standardization of pressure during blood flow restricted exercise. Eur J Appl Physiol. 2018 Feb;118(2):303-12.

27. Mouser JG, Dankel SJ, Mattocks KT, Jessee MB, Buckner SL, Abe T, et al. Blood flow restriction and cuff width: effect on blood flow in the legs. Clin Physiol Funct Imaging. 2018 Jan;38(6):944-8.

28. Mouser JG, Ade CJ, Black CD, Bemben DA, Bemben MG. Brachial blood flow under relative levels of blood flow restriction is decreased in a nonlinear fashion. Clin Physiol Funct Imaging. 2018 May;38(3):425-430.

29. Motykie GD, Zebala LP, Caprini JA, Lee CE, Arcelus JI, Reyna JJ, et al. A guide to venous thromboembolism risk factor assessment. J Thromb Thrombolys. 2000 Apr;9(3):253-262.

30. Earle, RW. Weight training exercise prescription. In: Essentials of Personal Training Symposium Workbook. Lincoln, NE: NSCA Certification Commission, 3-39, 2006.

31. Wu SP, Ringgaard S, Oyre S, Hansen MS, Rasmus S, Pedersen EM. Wall shear rates differ between the normal carotid, femoral, and brachial arteries: An in vivo MRI study. $J$ Magn Reson Imaging. 2004 Feb;19(2):188-93.

32. Newcomer SC, Sauder CL, Kuipers NT, Laughlin MH, Ray CA. Effects of posture on shear rates in human brachial and superficial femoral arteries. Am J Physiol Circ Physiol. 
2008 Apr;294(4):H1833-9.

33. Lixandrão ME, Ugrinowitsch C, Berton R, Vechin FC, Conceição MS, Damas F, et al. Magnitude of muscle strength and mass adaptations between high-load resistance training versus low-load resistance training associated with blood-flow restriction: a systematic review and meta-analysis. Sport Med. 2018 Feb;48(2):361-78.

34. Laurentino GC, Loenneke JP, Teixeira EL, Nakajima E, Iared W, Tricoli V. The effect of cuff width on muscle adaptations after blood flow restriction training. Med Sci Sports Exerc. 2016 May;48(5):920-5.

35. Abe T, Kearns CF, Sato Y. Muscle size and strength are increased following walk training with restricted venous blood flow from the leg muscle, Kaatsu-walk training. $J$ Appl Physiol. 2006 May;100(5):1460-6.

36. Karabulut M, Abe T, Sato Y, Bemben MG. The effects of low-intensity resistance training with vascular restriction on leg muscle strength in older men. Eur J Appl Physiol [Internet]. $2010 \mathrm{Jan} ; 108(1): 147-55$.

37. Ellefsen S, Hammarström D, Strand TA, Zacharoff E, Whist JE, Rauk I, et al. Blood flowrestricted strength training displays high functional and biological efficacy in women: a within-subject comparison with high-load strength training. Am J Physiol Integr Comp Physiol. 2015 Oct;309(7):R767-79.

38. Kubo K, Komuro T, Ishiguro N, Tsunoda N, Sato Y, Ishii N, et al. Effects of low-load resistance training with vascular occlusion on the mechanical properties of muscle and tendon. J Appl Biomech. 2006 May;22(2):112-9.

39. Lixandrão ME, Ugrinowitsch C, Laurentino G, Libardi CA, Aihara AY, Cardoso FN, et al. Effects of exercise intensity and occlusion pressure after 12 weeks of resistance training with blood-flow restriction. Eur J Appl Physiol. 2015 Dec;115(12):2471-80.

40. Ozaki H, Miyachi M, Nakajima T, Abe T. Effects of 10 weeks walk training with leg blood flow reduction on carotid arterial compliance and muscle size in the elderly adults. Angiology. 2011 Jan;62(1):81-6.

41. Pinto RR, Karabulut M, Poton R, Polito MD. Acute resistance exercise with blood flow restriction in elderly hypertensive women: haemodynamic, rating of perceived exertion and blood lactate. Clin Physiol Funct Imaging. 2018 Jan;38(1):17-24. 
Table 1: Percent change in blood flow response to occlusion pressures

Occlusion Pressures Percent Decrease in Blood Flow Percent of Resting Flow

\begin{tabular}{llc}
\hline 0 & 0.0 & 100.0 \\
10 & 23.4 & 76.6 \\
20 & 32.9 & 67.1 \\
30 & 36.1 & 63.9 \\
40 & 42.0 & 58.0 \\
50 & 47.6 & 52.4 \\
60 & 47.0 & 53.0 \\
70 & 48.8 & 51.2 \\
80 & 51.5 & 48.5 \\
90 & 71.0 & 29.0 \\
100 & 100.0 & 0.0 \\
\hline
\end{tabular}


Table 2: Summary of blood flow/pressure relationship

\begin{tabular}{|c|c|c|c|c|c|c|c|c|}
\hline $\begin{array}{l}\text { Percent } \\
\text { Arterial } \\
\text { Occlusion } \\
\text { Pressure }\end{array}$ & $\begin{array}{c}\text { Percent } \\
\text { Arterial } \\
\text { Occlusion } \\
\text { Pressure } \\
(\mathrm{mm} \mathrm{Hg}) \\
(\mathrm{SE}=5.74)\end{array}$ & $\begin{array}{c}\text { Vessel } \\
\text { Diameter } \\
(\mathrm{cm}) \\
(\mathrm{SE}=0.013)\end{array}$ & $\begin{array}{c}\text { Average } \\
\text { Flow } \\
(\mathrm{mL} / \mathrm{min}) \\
(\mathrm{SE}=6.43)\end{array}$ & $\begin{array}{c}\text { Antegrade } \\
\text { Flow } \\
(\mathrm{mL} / \mathrm{min}) \\
(\mathrm{SE}=6.71)\end{array}$ & $\begin{array}{c}\text { Retrograde } \\
\text { Flow } \\
(\mathrm{mL} / \mathrm{min}) \\
(\mathrm{SE}=3.44)\end{array}$ & $\begin{array}{l}\text { Diastolic } \\
\text { Blood } \\
\text { Pressure } \\
(\mathrm{mm} \mathrm{Hg}) \\
(\mathrm{SE}=2.4)\end{array}$ & $\begin{array}{c}\text { Systolic } \\
\text { Blood } \\
\text { Pressure } \\
(\mathrm{mm} \mathrm{Hg}) \\
(\mathrm{SE}=3.52)\end{array}$ & $\begin{array}{c}\text { Mean } \\
\text { Arterial } \\
\text { Pressure } \\
(\mathrm{mm} \mathrm{Hg}) \\
(\mathrm{SE}=2.55)\end{array}$ \\
\hline 0 & 0 & $0.567^{\mathrm{a}}$ & $125^{\mathrm{a}}$ & $163^{\mathrm{a}}$ & $38^{\mathrm{c}}$ & $65^{\mathrm{a}}$ & $114^{\mathrm{a}}$ & $84.00^{\mathrm{a}}$ \\
\hline 10 & $22^{\mathrm{a}}$ & $0.561^{\mathrm{a}, \mathrm{b}}$ & $96^{\mathrm{b}}$ & $138^{\mathrm{b}}$ & $43^{b, c}$ & $62^{\mathrm{a}}$ & $109^{\mathrm{a}}$ & $80.00^{\mathrm{a}}$ \\
\hline 20 & $43^{b}$ & $0.554^{\mathrm{a}, \mathrm{b}}$ & $84^{\mathrm{b}, \mathrm{c}}$ & $131^{\mathrm{b}}$ & $47^{\mathrm{a}, \mathrm{b}, \mathrm{c}}$ & $62^{\mathrm{a}}$ & $108^{\mathrm{a}}$ & $81.00^{\mathrm{a}}$ \\
\hline 30 & $65^{c}$ & $0.550^{\mathrm{a}, \mathrm{b}}$ & $80^{\mathrm{b}, \mathrm{c}, \mathrm{d}}$ & $133^{b}$ & $53^{\mathrm{a}, \mathrm{b}}$ & $64^{\mathrm{a}}$ & $109^{\mathrm{a}}$ & $82.00^{\mathrm{a}}$ \\
\hline 40 & $86^{\mathrm{d}}$ & $0.543^{\mathrm{a}, \mathrm{b}}$ & $73^{\mathrm{c}, \mathrm{d}}$ & $126^{\mathrm{b}}$ & $54^{\mathrm{a}, \mathrm{b}}$ & $65^{\mathrm{a}}$ & $112^{\mathrm{a}}$ & $83.00^{\mathrm{a}}$ \\
\hline 50 & $108^{\mathrm{e}}$ & $0.538^{b}$ & $66^{\mathrm{c}, \mathrm{d}}$ & $122^{\mathrm{b}, \mathrm{c}}$ & $56^{\mathrm{a}}$ & $63^{a}$ & $112^{\mathrm{a}}$ & $81.00^{\mathrm{a}}$ \\
\hline 60 & $129^{f}$ & $0.536^{\mathrm{b}}$ & $66^{\mathrm{c}, \mathrm{d}}$ & $121^{\mathrm{b}, \mathrm{c}}$ & $54^{\mathrm{a}, \mathrm{b}}$ & $62^{\mathrm{a}}$ & $112^{\mathrm{a}}$ & $80.00^{\mathrm{a}}$ \\
\hline 70 & $150^{\mathrm{g}}$ & $0.536^{\mathrm{b}}$ & $64^{\mathrm{c}, \mathrm{d}}$ & $104^{c}$ & $40^{c}$ & $61^{\mathrm{a}}$ & $105^{\mathrm{a}}$ & $78.00^{\mathrm{a}}$ \\
\hline 80 & $172^{\mathrm{h}}$ & $0.535^{\mathrm{b}}$ & $61^{\mathrm{d}}$ & $79^{d}$ & $18^{\mathrm{d}}$ & $66^{\mathrm{a}}$ & $114^{\mathrm{a}}$ & $84.00^{\mathrm{a}}$ \\
\hline 90 & $193^{\mathrm{i}}$ & $0.496^{c}$ & $36^{\mathrm{e}}$ & $43^{e}$ & $7^{\mathrm{d}, \mathrm{e}}$ & $62^{\mathrm{a}}$ & $107^{\mathrm{a}}$ & $80.00^{\mathrm{a}}$ \\
\hline 100 & $215^{j}$ & $0.464^{\mathrm{d}}$ & $0^{\mathrm{f}}$ & $0^{f}$ & $0^{\mathrm{e}}$ & $63^{a}$ & $108^{\mathrm{a}}$ & $81.00^{\mathrm{a}}$ \\
\hline
\end{tabular}

Blood flow/pressure relationship for each \%AOP (0\% to 100\%). Values not connected by the same letter are significantly different within each column $(\mathrm{p}<0.01)$. Standard error $=\mathrm{SE}$. 
Table 3: Summary of blood flow and hemodynamic measurements for within-group comparisons

\begin{tabular}{|c|c|c|c|c|c|c|c|}
\hline & $\begin{array}{c}\text { Average Blood } \\
\text { Flow }(\mathrm{mL} / \mathrm{min}) \\
(\mathrm{SE}=14.45)\end{array}$ & $\begin{array}{l}\text { Systolic } \\
\text { Blood } \\
\text { Pressure } \\
(\mathrm{mm} \mathrm{Hg}) \\
(\mathrm{SE}=2.43)\end{array}$ & $\begin{array}{c}\text { Diastolic } \\
\text { Blood Pressure } \\
(\mathrm{mm} \mathrm{Hg}) \\
(\mathrm{SE}=1.93)\end{array}$ & $\begin{array}{c}\text { Mean } \\
\text { Arterial } \\
\text { Pressure } \\
(\mathrm{mm} \mathrm{Hg}) \\
(\mathrm{SE}=1.96)\end{array}$ & $\begin{array}{c}\text { Heart } \\
\text { Rate }(\mathrm{bpm}) \\
(\mathrm{SE}=1.42)\end{array}$ & $\begin{array}{c}\text { Cardiac } \\
\text { Output } \\
(\mathrm{mL} / \mathrm{min}) \\
(\mathrm{SE}=0.12)\end{array}$ & $\begin{array}{c}\text { Stroke } \\
\text { Volume } \\
(\mathrm{mL} / \mathrm{Min}) \\
(\mathrm{SE}=0.02)\end{array}$ \\
\hline$\overline{\text { REST }}$ & $116^{\mathrm{a}}$ & $109.68^{\mathrm{a}, \mathrm{b}}$ & $62.72^{\mathrm{a}}$ & $81.50^{\mathrm{a}, \mathrm{b}}$ & $65.75^{\mathrm{a}}$ & $5.84^{\mathrm{a}}$ & $0.09^{\mathrm{a}}$ \\
\hline EP1 & $356^{\mathrm{b}}$ & $113.24^{\mathrm{a}, \mathrm{b}}$ & $66.06^{\mathrm{a}, \mathrm{b}, \mathrm{c}}$ & $84.31^{\mathrm{a}, \mathrm{b}}$ & $71.85^{\mathrm{b}, \mathrm{c}, \mathrm{d}}$ & $6.00^{\mathrm{a}, \mathrm{b}}$ & $0.08^{\mathrm{a}}$ \\
\hline RP1 & $174^{\mathrm{c}}$ & $109.00^{\mathrm{b}}$ & $63.29^{\mathrm{a}, \mathrm{b}}$ & $81.14^{\mathrm{b}}$ & $60.4^{\mathrm{b}}$ & $6.10^{\mathrm{b}}$ & $0.09^{\mathrm{a}}$ \\
\hline EP2 & $266^{\mathrm{d}}$ & $112.36^{\mathrm{a}, \mathrm{b}}$ & $65.38^{\mathrm{a}, \mathrm{b}, \mathrm{c}}$ & $83.72^{\mathrm{a}, \mathrm{b}}$ & $71.96^{\mathrm{c}, \mathrm{d}}$ & $5.99^{\mathrm{a}, \mathrm{b}}$ & $0.08^{\mathrm{a}}$ \\
\hline RP2 & $171^{\mathrm{c}}$ & $110.72^{a, b}$ & $64.65^{\mathrm{a}, \mathrm{b}, \mathrm{c}}$ & $82.41^{\mathrm{a}, \mathrm{b}}$ & $69.58^{\mathrm{b}, \mathrm{c}}$ & $6.09^{\mathrm{b}}$ & $0.09^{\mathrm{a}}$ \\
\hline EP3 & $263^{\mathrm{d}}$ & $115.04^{\mathrm{a}, \mathrm{b}}$ & $67.37^{\mathrm{b}, \mathrm{c}}$ & $85.71^{\mathrm{a}}$ & $72.81^{\mathrm{d}}$ & $6.03^{\mathrm{a}, \mathrm{b}}$ & $0.08^{\mathrm{a}}$ \\
\hline RP3 & $168^{a, c}$ & $113.33^{\mathrm{a}, \mathrm{b}}$ & $65.76^{\mathrm{a}, \mathrm{b}, \mathrm{c}}$ & $83.80^{\mathrm{a}, \mathrm{b}}$ & $70.39^{\mathrm{b}, \mathrm{c}, \mathrm{d}}$ & $6.15^{\mathrm{b}}$ & $0.09^{\mathrm{a}}$ \\
\hline EP4 & $261^{\mathrm{d}}$ & $115.39^{\mathrm{a}}$ & $67.70^{\mathrm{c}}$ & $85.87^{\mathrm{a}}$ & $72.46^{\mathrm{d}}$ & $6.01^{\mathrm{a}, \mathrm{b}}$ & $0.13^{\mathrm{a}}$ \\
\hline RP4 & $178^{\mathrm{c}}$ & $112.90^{\mathrm{a}, \mathrm{b}}$ & $65.91^{\mathrm{a}, \mathrm{b}, \mathrm{c}}$ & $83.85^{\mathrm{a}, \mathrm{b}}$ & $71.14^{\mathrm{b}, \mathrm{c}, \mathrm{d}}$ & $6.17^{\mathrm{b}}$ & $0.12^{\mathrm{a}}$ \\
\hline
\end{tabular}

Within-group comparisons of hemodynamics factors and average blood flow for rest and exercise periods 1-4 (EP) and rest periods 1-4 (RP). Values not connected by the same letter are significantly different within each column $(p<0.01)$. Standard error $=S E$. 


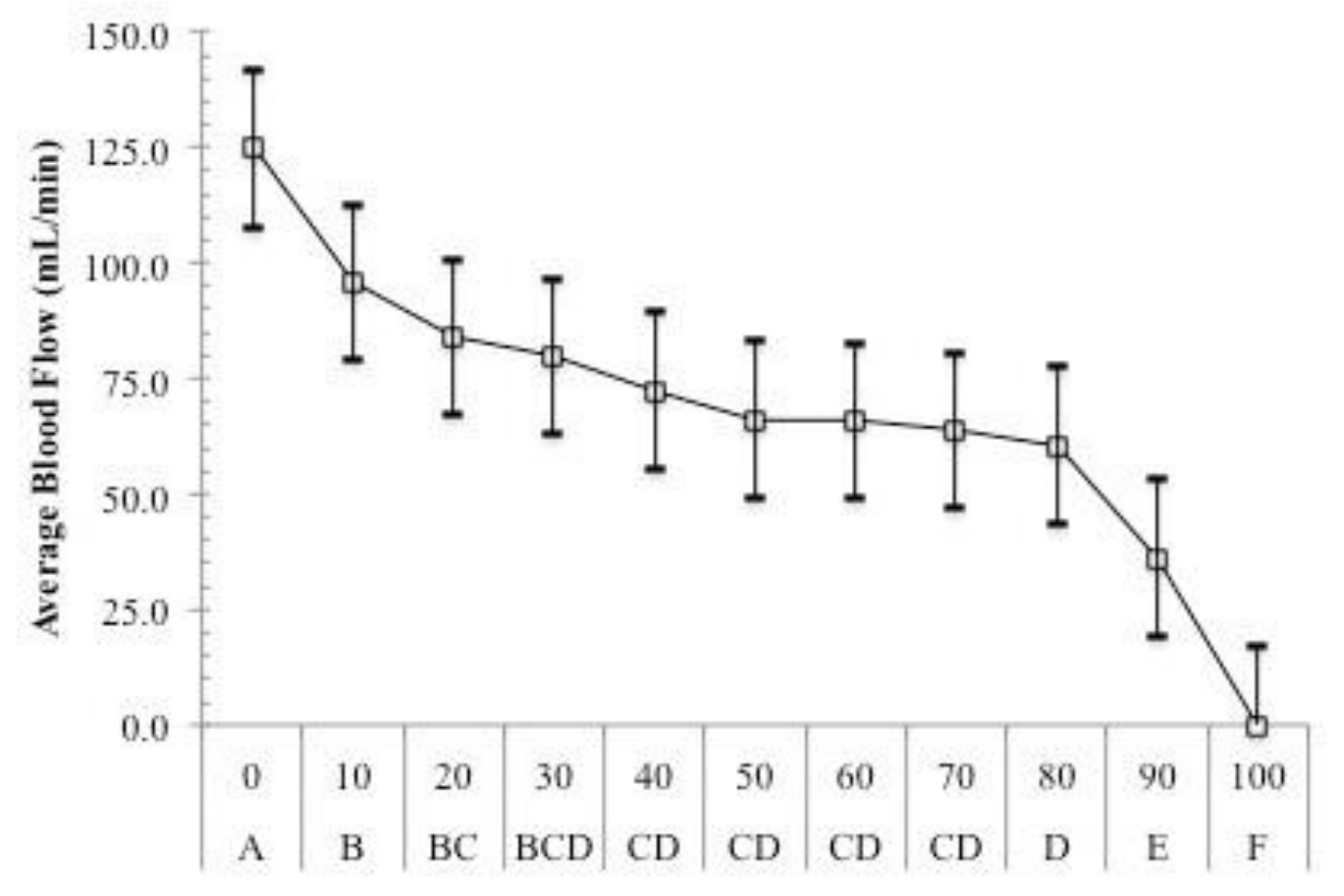

Arterial Occlusion Pressures by Percentages

Figure 1: Blood flow/pressure relationship. Average blood flow (mL.min) plot for each \%AOP and respective confidence intervals (CIs) (99\%). Pressures not connected by the same letter are significantly different $(\mathrm{p}<0.01)$. 


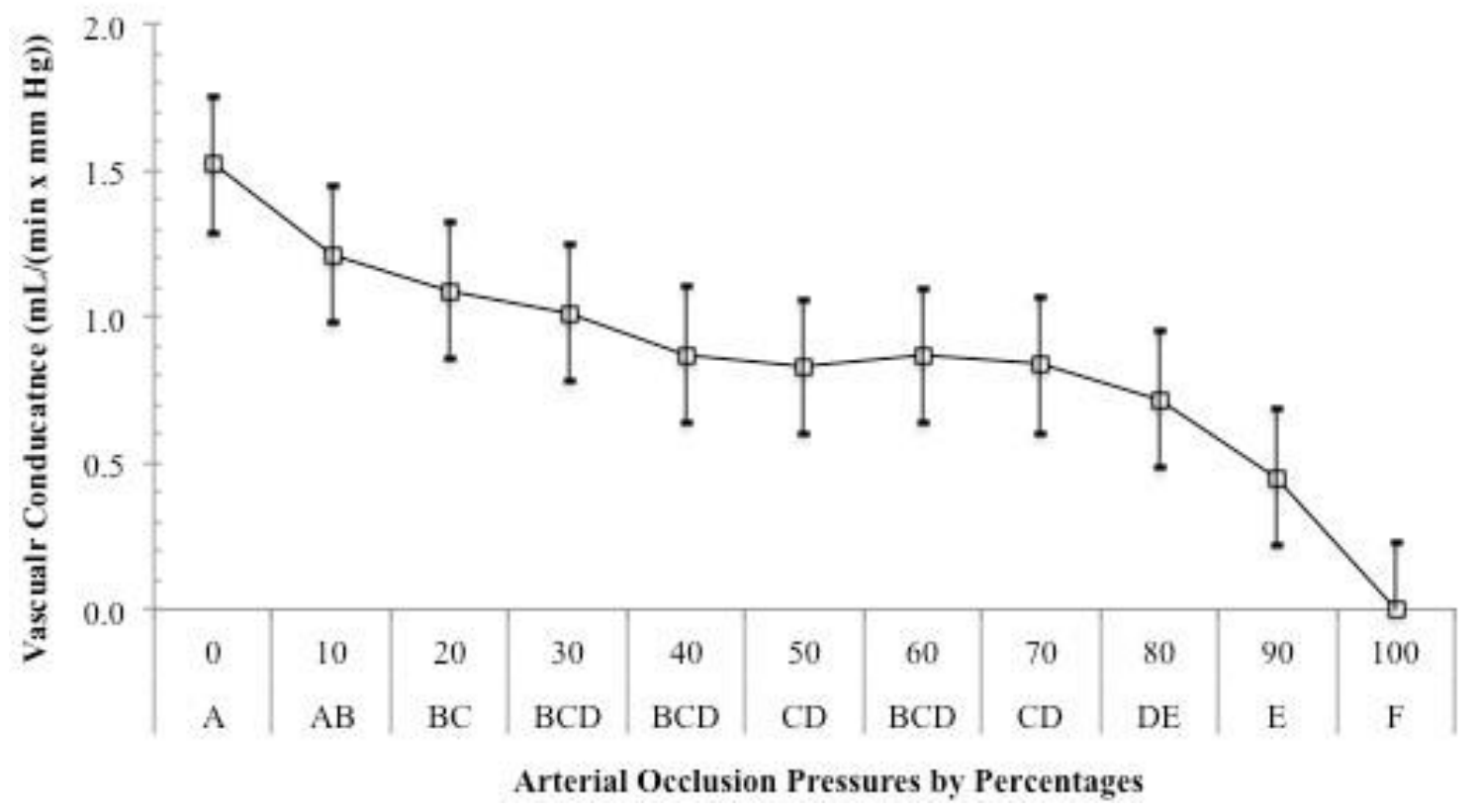

Figure 2: Vascular conductance (average blood flow / MAP) by \%AOPs with respective CIs $(99 \%)$. Pressures not connected by the same letters are significantly different $(\mathrm{p}<0.01)$. 


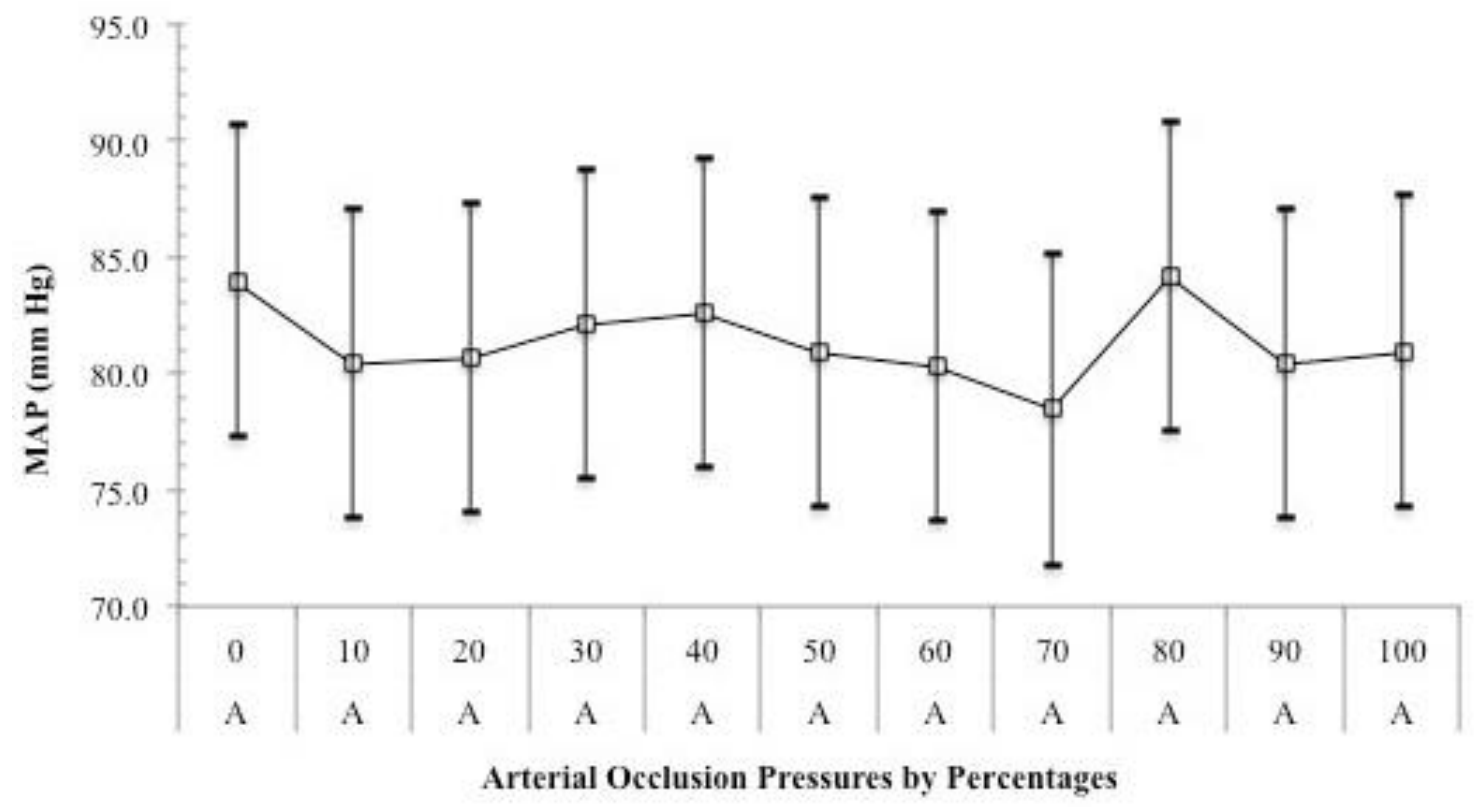

Figure 3: MAP by \%AOP plot with respective CIs (99\%). Pressures not connected by the same letter are significantly different $(\mathrm{p}=0.8)$. 

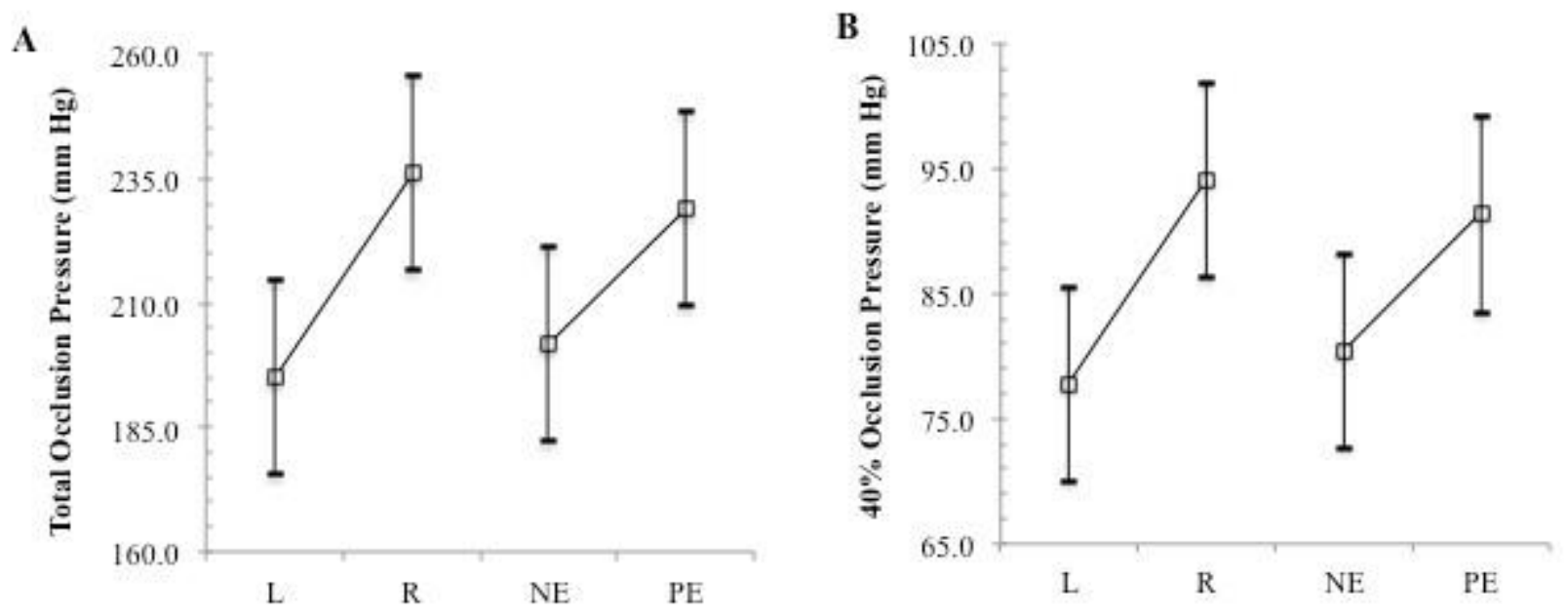

Figure 4: AOP and 40\% AOP for left and right legs as well as NE and PE groups. A) AOP for left and right legs as well as NE and PE groups, B) 40\% AOP for legs and Groups $(p<0.01)$. Confidence intervals included (99\%). Note the difference in scale between the graphs. 


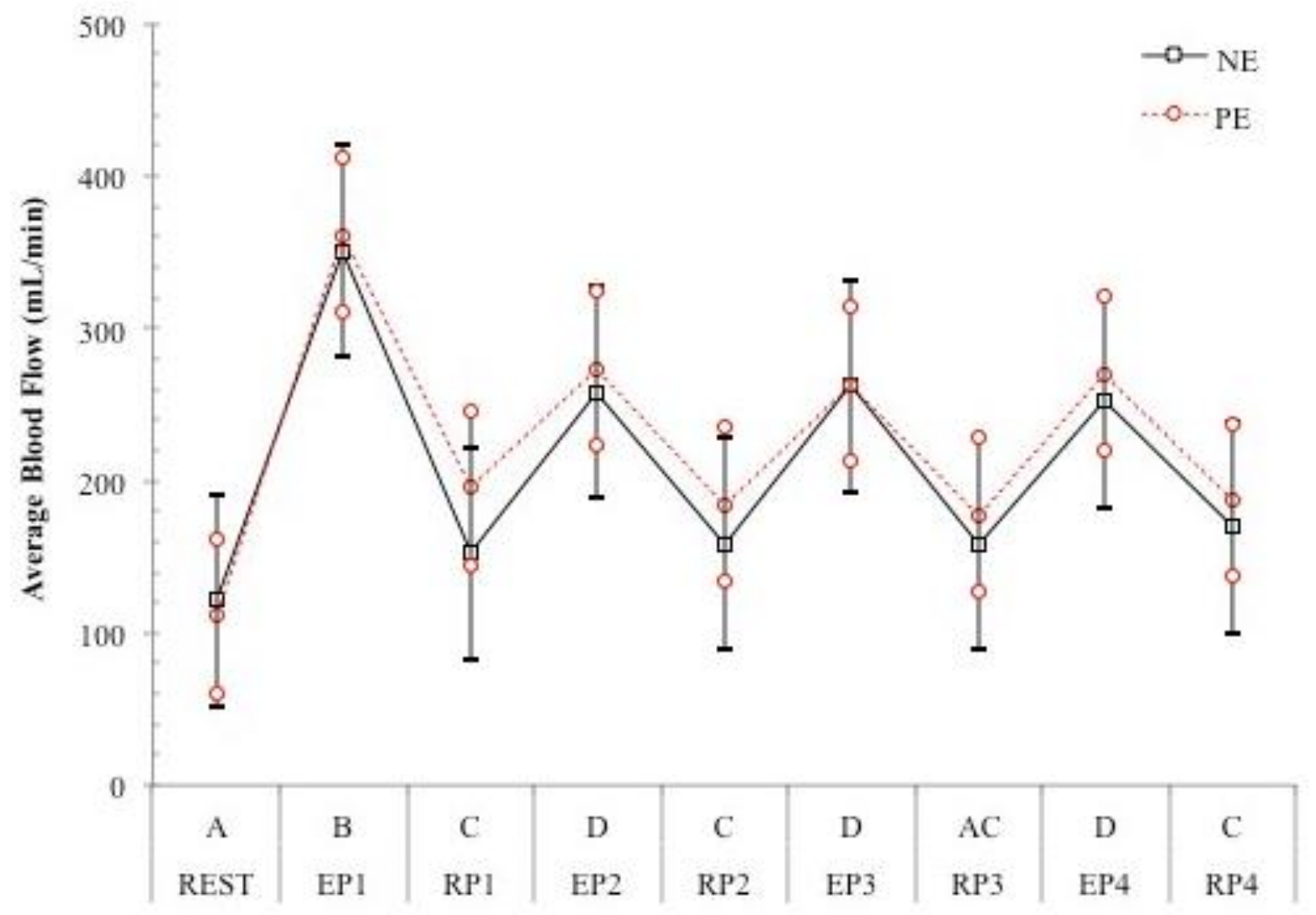

Figure 5: Blood flow comparisons between no exercise and preexercise. No significant difference in blood flow between NE and PE groups (confidence intervals included 99\%). However, there is significance in blood flow within groups. Measurements not connected by the same letter are significantly different $(\mathrm{p}<0.01)$. 